Int. J. Dev. Biol. 57: 265-272 (2013)

doi: 10.1387/ijdb.130146ja

\title{
Causes and consequences of apoptosis in spermatozoa; contributions to infertility and impacts on development
}

\author{
R. JOHN AITKEN* and MARK A. BAKER \\ Discipline of Biological Sciences and Priority Research Centre in Reproductive Science, Faculty of Science and IT, \\ University of Newcastle, Australia
}

\begin{abstract}
During early development, apoptosis plays a major role in the ontogeny of the germ line as a means of regulating the germ cell:Sertoli cell ratio. In the adult, apoptosis fulfils another function in removing damaged germ cells from the seminiferous epithelium in response to a wide range of physiological and environmental triggers. These include various forms of electromagnetic radiation, chemotherapeutic agents and commonly encountered toxicants such as phthalate esters, bisphenol A and cadmium. This form of apoptosis can lead to spermatogenic arrest and is predominantly mediated by the Fas/FasL system. In addition, senescent mature spermatozoa can undergo a truncated form of apoptosis in order to ensure their efficient phagocytosis within the male and female reproductive tracts. This apoptotic cascade appears to be triggered by oxidative stress and lipid peroxidation, which leads to activation of mitochondrial reactive oxygen species (ROS) generation in a self-perpetuating redox cycle. The electrophilic aldehydes generated as a result of lipid peroxidation also lead to a rapid loss of sperm motility followed some hours later by caspase activation and phosphatidylserine exposure on the sperm surface. The nuclear DNA suffers oxidative damage during this process but there is no immediate DNA cleavage by endonucleases as there is in somatic cells. The reasons for this deviation from the normal pattern of apoptosis involve the unusual physical architecture of spermatozoa and the limited capacity these cells possess for base-excision repair. These findings have practical implications for the approaches that might be used to detect and prevent DNA damage in spermatozoa.
\end{abstract}

KEY WORDS: spermatozoa, apoptosis, reactive oxygen species, mitochondria DNA damage

\section{Apoptosis and male germ cell development}

Apoptosis is a major feature of male germ cell development that orchestrates the production and function of these cells from the early stages of gonadal differentiation to the moment of fertilization. Towards the end of embryogenesis a major wave of germ cell apoptosis occurs in prospermatogonia/gonocytes when the testes are differentiating and adjustments have to be introduced to achieve the optimal germ cell:Sertoli cell ratio. During this developmental process, excess premeiotic spermatogonia are removed by apoptosis during the first round of spermatogenesis in the testis. Impairment of apoptosis through the functional deletion of key mediators of this process generates a male infertility phenotype due to an imbalance in germ- and Sertoli- cell numbers (Rodriguez et al., 1997). This regulatory role for apoptosis in the male germ cell development is very similar to the situation in the differentiating female gonad where there is also a wave of apoptosis in the ovary as germ cells are eliminated that have not found somatic cells with which to form primordial follicles (Aitken et al., 2011).

In adulthood, apoptosis again plays a significant role in regulating germ cell development. For example, apoptosis is used as a mechanism for removing damaged germ cells from seminiferous tubules so that they do not continue to differentiate into spermatozoa. Selective deletion of damaged germ cells is clearly a critical component of the mechanisms used to safeguard the genome of a given species. The range of stimuli that will trigger this activity is impressively broad including various forms of electromagnetic radiation, environmental toxicants, heavy metals and chemotherapeutic agents (Xu et al., 1999; Wang et al., 2007; Li et al., 2009; Alam et al., 2010; Shaha et al., 2010). In addition, genetic perturbance of the germ line through, for example, overexpression of SPATA 17

Abbreviations used in this paper: ROS, reactive oxygen species.

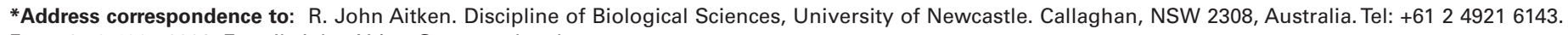
Fax: +61-2-4921-6308. E-mail: John.Aitken@newcastle.edu.au
}

Final, author-corrected PDF published online: 5 June 2013.

ISSN: Online 1696-3547, Print 0214-6282 
(Nie et al., 2012) or androgen binding protein (Jeyaraj et al., 2003) or deletion of key genes involved in the regulation of spermatogenesis such as gonadotropin-regulated testicular helicase (GRTH)/ DDX25) (Gutti et al., 2008), Jmjd1a demethylase (Liu et al., 2010) Crem (Kosir et al., 2012) or several molecular chaperones (Grad et al., 2010; Held et al., 2011) increases the level of apoptosis observed in the male germ line. Similarly, endocrine disruption of spermatogenesis through the induction of diabetes with streptozotocin (Tsounapi et al., 2012) or exposure to estrogen as an adult, but not in utero, leads to the induction of apoptosis in male germ cells (Ma et al., 2008; Chimento et al., 2010; LaRocca et al., 2011). The impression given is that if spermatogenesis is disrupted in any way then the germ cells tend to default to an apoptotic state. The stage of spermatogenesis when apoptosis is induced appears to be predominantly pachytene spermatocytes and the Fas/FasL system appears to be a major mediator of this process (Lin et al., 2010). The inherent sensitivity of the male germ line to apoptosis also extends to testicular germ cell tumours, which readily default to this state in the presence of chemotherapeutic agents such as cisplatin (Spierings et al., 2003).

Apoptosis during spermatogenesis has also been suggested to play a role in the aetiology of spontaneous male infertility in light of the excessively high numbers of apoptotic germ cells observed in the testes of some infertile males (Lin et al., 1997). In addition, apoptotic markers including caspase activation and phosphatidylserine exteriorization have been detected in the mature spermatozoa of male infertility patients (Barroso et al., 2000; Paasch et al., 2004; Grunewald et al., 2009; Almeida et al., 2009; Aitken and Curry 2011). Since apoptosis in mature spermatozoa appears to be critically involved in the induction of a subfertile state associated with high levels of DNA damage, it is this aspect of the apoptotic process that we shall focus on in the remainder of this review.

\section{Apoptosis and sperm survival}

A fundamental feature of apoptosis in the mature spermatozoon is that this process represents a default position for the cell. Indeed, it is the fate of every spermatozoon in the ejaculate to undergo an apoptotic death, apart from the few spermatozoa that achieve immortality by successfully fertilizing oocytes. For most spermatozoa apoptosis is not induced but is a spontaneous consequence of their strenuous attempts to reach the oocyte and engage in the process of fertilization. When spermatozoa are inseminated into the female reproductive tract they are incapable of recognizing the egg or engaging in the cascade of cellular interactions that will culminate in fertilization. Before fertilization can occur these cells have to undergo a maturation process in the female tract known as 'capacitation'(Baker et al., 2012). This process allows spermatozoa to orchestrate the assembly and presentation of a complex array of receptors on their surface for the zona pellucida (Reid et al., 2011). In addition, capacitation is associated with the expression of a highly specialized form of motility known as 'hyperactivation', which allows the spermatozoa to generate the propulsive forces necessary to detach themselves from the epithelium lining the oviductal isthmus and penetrate through the vestments surrounding the oocyte (Suarez, 2008).

The chemical basis of sperm capacitation is still being resolved in detail but it is known to involve a loss of cholesterol from the plasma membrane and a global increase in tyrosine phosphoryla- tion, particularly on the sperm tail, under the influence of cAMP (Bailey, 2010). This entire process appears to be redox regulated (Aitken et al., 1995, 1998) and dependent on a low level of ROS generation by the spermatozoa. The ROS involved in this process are generated in a bicarbonate-dependent process (Ecroyd et al., 2003; Boerke et al., 2013) that may involve the sperm mitochondria (Koppers et al., 2008) and/or a plasma membrane NADPH oxidase such as Nox5 (Musset et al., 2012). The superoxide $\left(\mathrm{O}_{2}^{-\bullet}\right)$ generated from these sites combines with nitric oxide to generate a powerful reactive nitrogen species (RNS), peroxynitrite (ONOO-). This combination of $\mathrm{O}_{2}-\bullet$ and ONOO- serves to suppress tyrosine phosphatase activity in the spermatozoa and simultaneously activate adenylyl cyclase (Lewis and Aitken, 2001). The net result of these actions is to stimulate the tyrosine phosphorylation cascade that drives sperm capacitation. The ROS generated during capacitation also oxidize cholesterol to form oxysterols and induce the simultaneous activation of a reverse sterol transport system from the sperm surface (Boerke et al., 2013). The depletion of cholesterol from the plasma membrane via such mechanisms increases the latter's fluidity and in so doing facilitates a fertilization process that is highly dependent on acts of membrane fusion.

Spermatozoa can, however, ultimately have too much of a good thing. The continuous generation of RNS and ROS by these cells during capacitation eventually overwhelms their limited defensive capabilities and creates a state of oxidative stress that then triggers the intrinsic apoptotic cascade (Aitken, 2011; Fig. 1). Thus, apoptosis in spermatozoa is not triggered at cell cycle checkpoints as in somatic cells but rather represents a form of programmed senescence. The reason for such a carefully controlled cell death may be related to the interaction between spermatozoa and the immune system. In both men and women, spermatozoa are regarded as foreign cells that are potentially immunogenic and capable of generating both humoral and cell-mediated immune responses. When spermatozoa become senescent, it is critical that they are removed by a phagocytotic process that is silent, in the sense that no pro-inflammatory cytokines are produced. If this were not the case, a phlogistic response might be generated that would ultimately result in the induction of immunity against sperm antigens and infertility (Koppers et al., 2011). In other cellular systems where silent phagocytosis is observed, as in the removal of neutrophils by macrophages during the resolution of acute inflammatory responses, the expression of apoptotic markers, such as phosphatidylserine, on the surface of the target cell is critical in suppressing the immune response (Fadok et al., 1992; Savill et al., 2002; Devitt and Marshall, 2011). By engaging in a regulated cell death exhibiting many of the features of apoptosis, moribund spermatozoa ensure that they can be efficiently removed from the male or female reproductive tract without provoking a damaging inflammatory response. This facility is particularly important in the female reproductive tract where hundreds of millions of spermatozoa are removed by phagocytosis in the hours following insemination (Thompson et al., 1992; Rozeboom et al., 1998).

In this context, it is worth considering the consequences of using a detergent-based spermicide such as nonoxynol 9, which would be expected to destroy the architecture of the sperm surface and prevent the presentation of apoptotic markers to the immune system. Careful studies have been performed on the induction of proinflammatory cytokines by spermicidal compounds in isolation (Fichorova et al., 2004), but it is the response elicited by the com- 
bined presence of spermicide and spermatozoa, which is really critical. It may well be that the use of spermicides renders women particularly susceptible to HIV infection (Van Damme et al., 2002) as a consequence of localized inflammatory reactions that have been induced because the protective action of apoptosis has been counteracted by the chemical disruption of the sperm surface.

\section{The apoptotic process in spermatozoa}

The highly specialized differentiated state of spermatozoa has implications for the form that apoptosis ultimately takes. Because apoptosis appears to be a default position for these cells, the key question that arises is not "What induces apoptosis in spermatozoa?" but rather, "What prevents this process from occurring?" This is a particularly pertinent question for human spermatozoa. We are unique amongst mammalian species because there is no behavioural estrus to ensure that insemination is synchronized with ovulation. As a result, human spermatozoa may have to survive for a week in the female tract waiting for ovulation to occur. Such prolonged survival depends on the presence of prosurvival factors such as prolactin or insulin in the reproductive tract fluids (Pujianto et al., 2010). Such factors, in turn, exert their anti-apoptotic effects by promoting the activation of a key enzyme, phosphatidylinositide 3-kinase (PI3 kinase) responsible for the generation of phosphatidylinositol $(3,4,5)$-triphosphate (Ptdlns(3,4,5)P3), otherwise known as PIP3.

One of the characteristic features of human spermatozoa, which defines the control of apoptosis in this cell type, is its high level of compartmentalization. Thus an antibody against the p100 kD catalytic subunit of PI3 kinase reveals this enzyme to be located in the principal piece of the sperm tail, the neck and the acrosome but to be excluded from the midpiece of the cell where the mitochondria and residual cytoplasm are located (Fig. 2A). In most cells, the ability of PI3 kinase to generate PIP3 is in dynamic equilibrium with a phosphatase that negatively regulates the bioavailability of this phosphoinositide by catalyzing its dephosphorylation to the corresponding biphosphate, PIP2 (Ptdlns(4,5)P2). This phosphatase is known as phosphatase and tensin homolog (PTEN). Immunocytochemical localization of PTEN generates a very weak signal, predominantly in the mid piece of the cell. However, an antibody against the phosphorylated, stabilized, form of this enzyme (pSer380), has revealed that a majority of the PTEN in spermatozoa exists in a phosphorylated state and is localized in the equatorial segment of the sperm head, completely separated from $\mathrm{PI} 3$ kinase in the sperm neck, tail and anterior acrosome (Fig. 2A). This physical separation of PI3 kinase and phosphorylated PTEN is absolutely unique to spermatozoa and serves to ensure that the former is completely free to generate PIP3 without any interference from PTEN phosphatase activity.

The PIP3 generated by activated PI3 kinase binds to another serine/thronine kinase, AKT, and facilitates the transfer of the latter to the plasma membrane where it becomes phosphorylated. Phosphorylated AKT is then responsible for activating a variety of downstream pathways, which ensure that the spermatozoa do not become senescent and apoptosis is held in abeyance. Two of the three major isoforms of AKT expressed in the testes are AKT1 (RACalpha serine/threonine-protein kinase), a recognized inhibitor of apoptosis and AKT2 (RAC-beta serine/threonine-protein kinase), an important constituent of the insulin signaling pathway. Immunocytochemical studies have revealed that the former is present throughout the sperm tail, particularly the sperm midpiece, where the life-death decisions for spermatozoa are made (Fig. 2 B). AKT2 is also strongly present in the midpiece of the cell and, to a lesser extent, the proximal part of the tail principal piece; however, in contrast to AKT1, AKT2 also gives a very strong signal in the sperm head, particularly in the vicinity of the acrosome (Fig. 2B). The activated, phosphorylated forms of this kinase including pThr34 AKT (present in AKT-1 but not AKT-2) as well as pThr308-, pSer473- and pSer124-AKT (represented in both AKT1 and AKT2) have also been detected in human spermatozoa. Significantly, all antibodies exhibited strong staining in the sperm midpiece, in close proximity to the sperm mitochondria (Fig. 2C).

Within the sperm midpiece the function of phosphorylated AKT is to prevent apoptosis. One of the ways in which this is achieved is

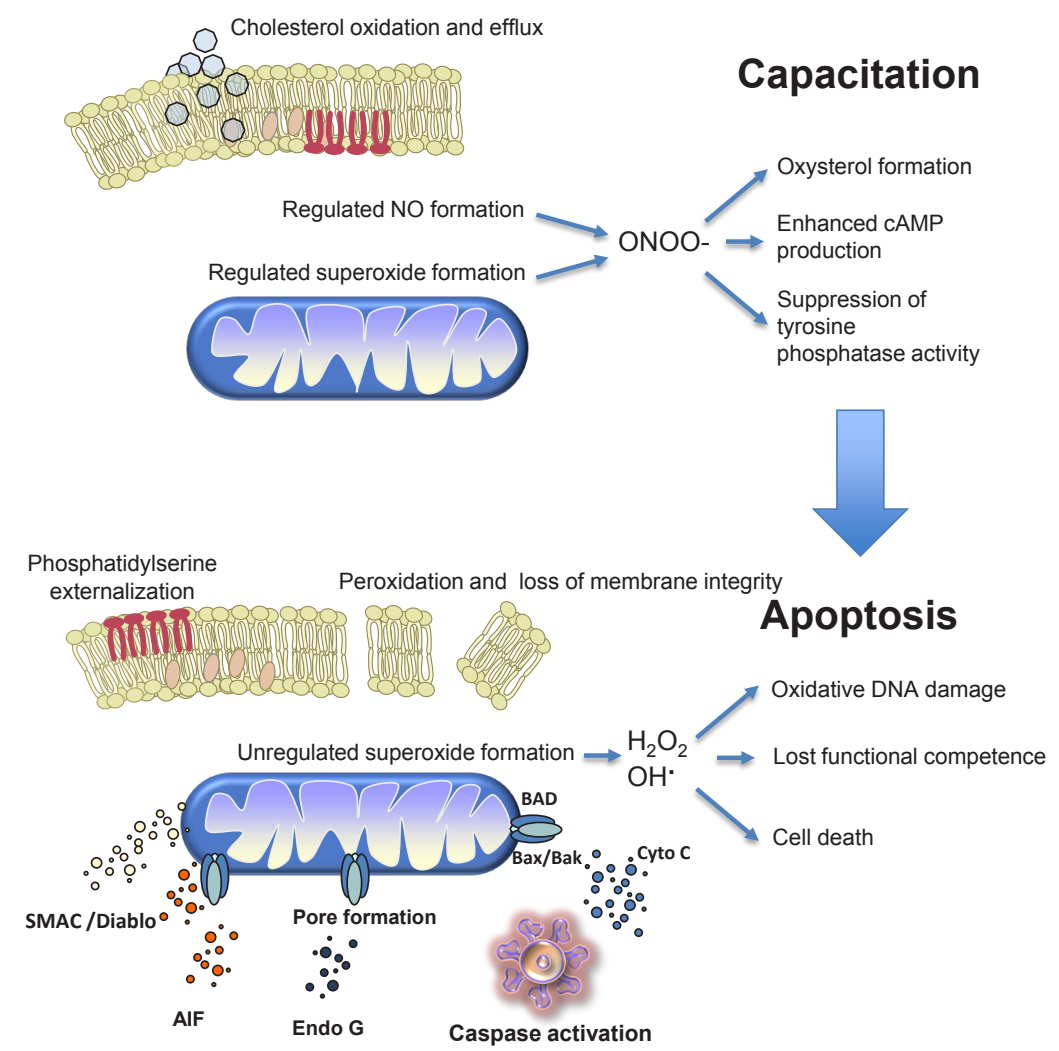

Fig. 1. Capacitation and apoptosis in mammalian spermatozoa. During capacitation the generation of ROS, particularly ONOO- leads to oxysterol production, which facilitates the removal of cholesterol from the plasmalemma and a consequential increase in membrane fluidity as well as other changes including tyrosine phosphatase inhibition and increased CAMP production. All of these changes promote acquisition of a capacitated state. If fertilization does not occur the continued generation of oxysterols and lipid aldehydes leads to the induction of apoptosis characterized by enhanced mitochondrial superoxide generation, lipid peroxidation, cytochrome C release, caspase activation, phosphatidylserine exposure, oxidative DNA damage and death (based on Aitken, 2011, reproduced with permission). 
by maintaining the pro-apoptotic factor, BAD, in a phosphorylated state. Using an antibody that could recognize the phosphorylated form of BAD (pSer99), this post-translationally modified protein has been detected in the midpiece and tail of control spermatozoa (Fig. $2 \mathrm{D})$. However, treatment with the PI3 kinase inhibitor, wortmannin, was found to induce complete loss of the pS99 epitope (Fig. $2 D)$. Since this sudden change in BAD phosphorylation would be expected to initiate the intrinsic apoptotic cascade, wortmannin can be used to synchronize the entry of spermatozoa into this pathway so that time-dependent studies can be conducted on the sequence of changes exhibited as these cells undergo apoptosis.

\section{Activation of mitochondrial reactive oxygen species generation during apoptosis}

One of the first signs that apoptosis has been activated by wortmannin is a sudden increase in the production of ROS from the sperm mitochondria (Aitken and Curry, 2011). The activation of mitochondrial ROS generation is not associated with any immediate change in mitochondrial membrane potential (Koppers et al., 2011) although, ultimately, the latter fails as spermatozoa enter an advanced state of senescence and start to lose viability (Espinoza et al., 2009). One of the major causes of sustained mitochondrial ROS generation in spermatozoa entering apoptosis, involves disruption of the mitochondrial electron transport chain by electrophilic aldehydes generated as a result of lipid peroxidation. Thus the primary trigger for activation of the intrinsic apoptotic cascade could, curious as it may sound, be the induction of a mild oxidative stress. The latter could arise in any number of ways including poor antioxidant protection within the male or female reproductive tract as a result of dietary deficiencies (Palmer et al., 2012), age (Weir and Robaire, 2007), varicocele (Mostafa et al., 2001), cryostorage (Thomson et al., 2009), exposure to lifestyle factors (Fraga et al.,
1996; Linschooten et al., 2011), medicinal compounds (Ghosh et al., 2002), bacteria (Villegas et al., 2005; Fraczek et al., 2007), prolonged incubation in vitro or in vivo (Balasuriya et al., 2013) and a range of environmental factors including non-ionizing radiation (Agarwal et al., 2009; De luliis et al., 2009). All such factors converge in the generation of oxidative stress within the spermatozoa. One of the inevitable consequences of oxidative stress in spermatozoa is the induction of high levels of lipid peroxidation. This occurs because spermatozoa are particularly well endowed with polyunsaturated fatty acids, particularly 22:6 (decosahexaenoic acid). The latter are particularly vulnerable to free radical attack because the carbon-hydrogen dissociation energies are lowest at the bis-allylic methylene position. As a result, the hydrogen abstraction event that initiates lipid peroxidation is promoted, generating a carbon centred lipid radical that then combines with oxygen to generate peroxyl (ROO•) and alkoxyl ( $\mathrm{RO} \cdot$ ) radicals that, in order to stabilize, abstract hydrogen atoms from adjacent carbons. These chemical reactions create additional lipid radicals that then perpetuate the lipid peroxidation chain reaction culminating in the generation of small molecular mass lipid aldehydes such as 4-hydroxynonenal (4HNE), acrolein and malondialdehyde.

These electrophilic aldehydes bind to multiple targets in spermatozoa particularly in the mitochondria. A major consequence of this activity is the induction of mitochondrial ROS activity. In Fig. $3 \mathrm{~A}$, the dose-dependent ability of electrophilic aldehydes such as acrolein and $4 \mathrm{HNE}$ to trigger ROS generation is illustrated (Aitken et al., 2012). Interestingly, the ability of electrophilic lipid peroxides to stimulate ROS generation by Michael addition reactions with mitochondrial proteins has been observed in other cell types (Landar et al., 2006). The lipid aldehyde-adducted proteins responsible for mitochondrial ROS generation have been investigated and appear to involve the flavoprotein component of succinic acid dehydrogenase (SDHA). Thus bromopyruvate, a known inhibitor of SDHA, has been
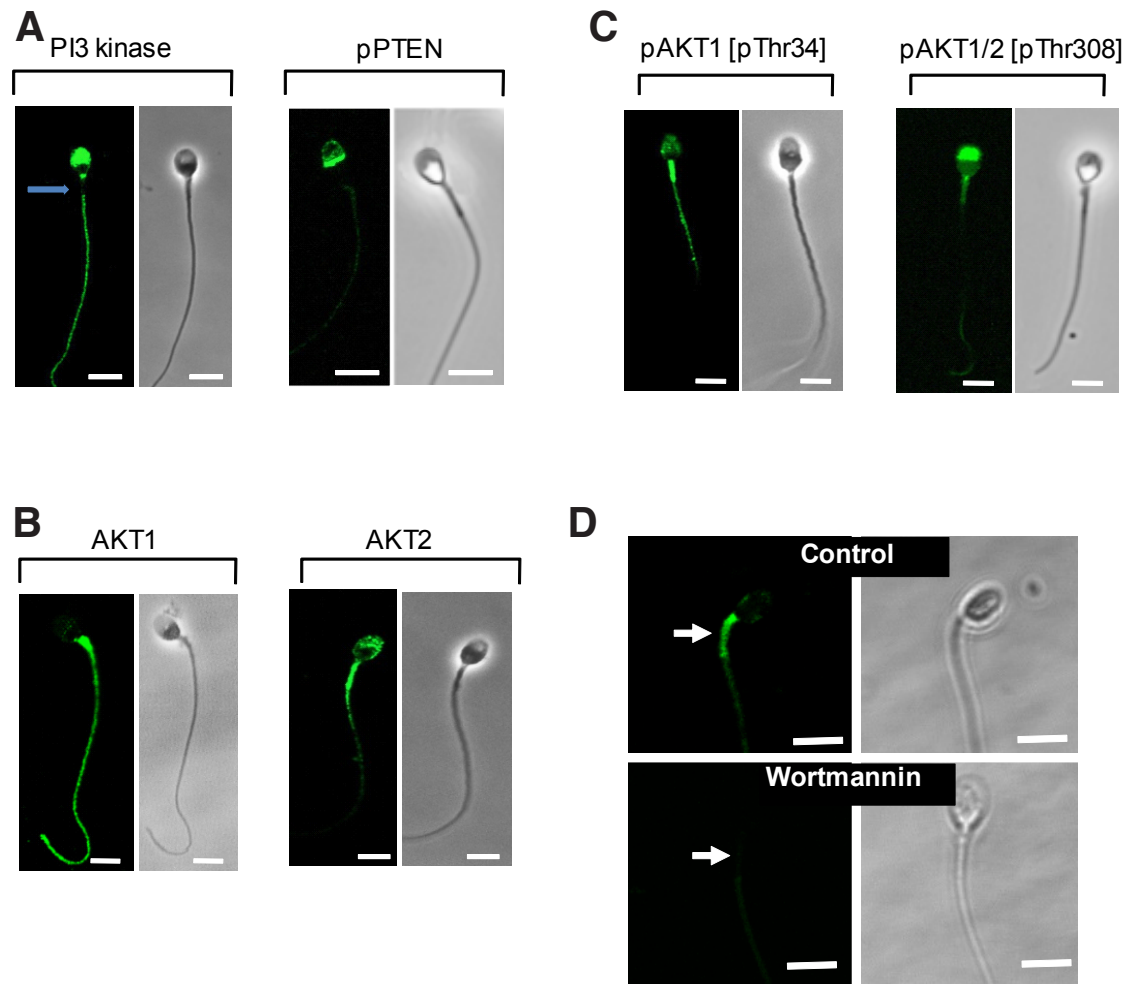

Fig. 2. PI3 kinase and AKT in human spermatozoa. Immunocytochemistry images showing the subcellular distributions for PI3 kinase and AKT. (A) PI3 kinase (p110 catalytic subunit) located in the acrosomal region, neck and principle piece of the sperm tail but no signal in the sperm midpiece (arrowed). Most PTEN is stabilized by phosphorylation and located in the equatorial segment of the sperm head. This physical separation of PI3K and PTEN is unique to spermatozoa and ensures that the former is maximally active. (B) Immunocytochemical analyses revealed the presence of $A K T 1$ along the entire length of the sperm tail including the neck, midpiece and principal piece, whereas AKT2 was principally located in the sperm acrosome and the midpiece, where the mitochondria are located. (C) The phosphorylated form of AKT1 (pThr34) generated a strong signal in the sperm tail with clear emphasis on the midpiece, whereas pThr308, (present in both AKT1 and AKT2) was found in the midpiece and in the acrosomal region. (D) The anti-apoptotic factor phospho-BAD is predominantly located in the midpiece of human spermatozoa (indicated by an arrow); however, all cross-reactivity is lost in the presence of the PI3 kinase inhibitor, wortmannin $(20 \mu \mathrm{M})$. Scale bars $=5 \mu \mathrm{m}$ (based Koppers et al., 2011; reproduced with permission). 
A
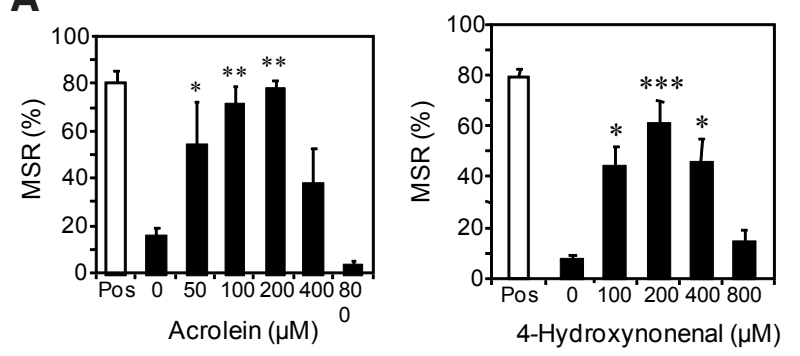

B

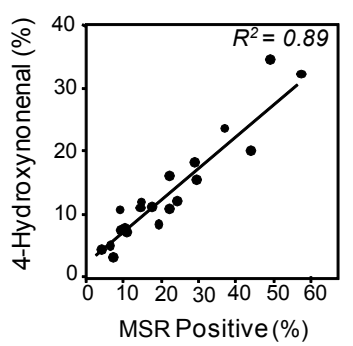

C

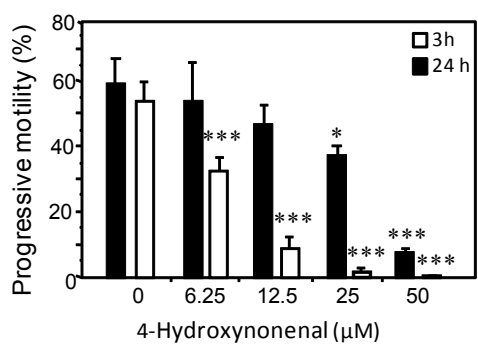

Fig. 3. Impact of lipid aldehydes on human sperm function. (A) Dosedependent changes in mitochondrial ROS generation detected with MitoSox red (MSR) following exposure to acrolein and 4-hydroxynonenal. (B) Linear correlation between mitochondrial ROS generation and 4-hydroxynonenal content of human spermatozoa. (C) Impact of 4-hydroxynonenal on the progressive motility of human spermatozoa after 3 hours (closed histogram) or 24 hours (open histogram) exposure. ${ }^{* *}{ }^{*} \mathrm{P}<0.001$; ${ }^{*} \mathrm{P}<0.01$; ${ }^{*} \mathrm{P}<$ 0.05. (based on Aitken et al., 2012; reproduced with permission).

shown to activate mitochondrial ROS generation in populations of human spermatozoa, while Western blot analyses involving whole cell lysates and immunoprecipitated $\mathrm{SDH}$, demonstrated the latter to be a major HNE-adducted protein in these cells (Aitken et al., 2012). Furthermore, the ability of the flavoprotein inhibitor DPI to suppress HNE-induced mitochondrial ROS generation by human spermatozoa is consistent with the involvement of SDHA (which contains a covalently attached flavin adenine dinucleotide cofactor) in this process (Aitken et al., 2012). This conclusion is also in keeping with the apparent importance of succinate in regulating mitochondrial ROS in other cell types (Zoccarato et al., 2009) and the fact that isolated $\mathrm{SDH}$ is capable of free radical generation (Zhang et al., 1998).

In light of the foregoing, it is possible that a wide range of factors are potentially capable of creating a mild oxidative stress in spermatozoa. The creation of such stress is followed by the generation of electrophilic lipid aldehydes such as 4HNE that then form adducts with susceptible proteins particularly at cysteine, histidine and lysine residues. In the case of sperm mitochondria, the formation of such adducts perturbs the flow of electrons along the mitochondrial electron transport chain resulting in electron leakage to oxygen and the formation of $\mathrm{O}_{2}-\cdot$. These observations accord with previous observations suggesting that ROS generation by human spermatozoa is triggered by oxidative stress in a self-perpetuating redox cycle (du Plessis et al., 2010). As a result of the positive feedback loop inherent in this cycle, once a state of oxidative stress has been created in spermatozoa, it will be very difficult to reverse. These observations are also consistent with the association that has been recorded between defective sperm

function and ROS generation by the sperm mitochondria (Koppers et al., 2008) and the fact that highly significant correlations $(P<$ 0.001 ) have been observed between the observed baseline 4HNE content of human spermatozoa and their spontaneous capacity for generating mitochondrial ROS $\left(R^{2}=0.89\right.$; Fig. 3B). Apoptosis in mammalian spermatozoa may therefore be a product of ROSinduced ROS generation, as has been observed in other cellular systems (Zorov et al., 2000).

\section{Disruption of sperm motility}

The formation of lipid adducts with sperm proteins is probably also responsible for another central feature of the apoptotic cascade in these cells, a loss of motility. If apoptosis is triggered by using wortmannin to suppress $\mathrm{PI} 3$ kinase activity, then a highly significant dose- $(P<0.001)$ and time- $(P<0.001)$ dependent loss of percentage sperm motility and progressive motility is observed (Koppers et al., 2011). Furthermore, addition of lipid aldehydes such as $4 \mathrm{HNE}$ and acrolein to human spermatozoa induces a dose-dependent loss of motility and progressive motility in human spermatozoa (Aitken et al., 2012). This suppression of movement can be achieved with concentrations of these electrophiles that are well within the physiological range. Thus, when cells are oxidatively stressed, the cellular concentrations of $4 \mathrm{HNE}$ are held to range between $10 \mu \mathrm{M}$ and $5 \mathrm{mM}$ (Chen and Niki, 2006; Uchida, 2003) while significant effects of this electrophile on sperm motility have been observed at doses above $6.25 \mu \mathrm{M}$ (Fig. 3C). This loss of sperm motility is, in all probability, due to the ability of electrophilic lipid aldehydes to adduct directly onto proteins that control sperm movement. It has been known for some time that alkylating agents such as benzoquinone can have a rapid immobilizing impact on mammalian spermatozoa, because they form covalent complexes with key proteins involved in the regulation of flagellar activity such as AKAP3 and AKAP4 as well as dynein (Hughes et al., 2009). Although alkylating agents are capable of activating ROS generation, particularly from the mitochondria (Aitken et al., 2012), this activity per se is not responsible for the sudden arrest of sperm movement. Alkylating agents that have no capacity to redox cycle, such as bismaleimide, can still instantly paralyse human spermatozoa (Hughes et al., 2009) whereas reagents, such as arachidonic acid, that induce mitochondrial ROS production but possess no alkylating activity take significantly longer to inhibit the movement characteristics of these cells (Aitken et al., 2006). Whatever fundamental mechanism is involved, this loss of motility during the early stages of apoptosis ensures that such defective spermatozoa do not participate in the process of fertilization.

\section{Markers of apoptosis}

Following the activation of mitochondrial ROS generation and the suppression of motility, spermatozoa exhibit many of the signatures of apoptosis including caspase activation and phosphatidylserine (PS) externalization (Barroso et al., 2000; Weng et al., 2002; Koppers et al., 2011). If the initiation of apoptosis is synchronized with wortmannin, then caspase activation can be seen to increase before PS exposure; thus while significant caspase activation is evident 4 hours after the initiation of apoptosis, PS exteriorization does not become manifest until 8 hours (Koppers et al., 2011). In such situations, caspase activation is presumably secondary 
to mitochondrial pore formation and the release of cytochrome $\mathrm{C}$ (Ortega Ferrusola et al., 2010; Koppers et al., 2011). Mitochondrial pore formation and caspase activation would, in turn, be expected to promote the activation of endonucleases which are either released from the mitochondrial inter-membranous space, (Apoptosis Inducing Factor, mitochondrion-associated [AIFM] or endonuclease $\mathrm{G}$ [EndoG]), or activated in the cytosol (Caspase Activated DNase; CAD), prior to their translocation to the nucleus. Such apoptosis-associated endonuclease activity has been proposed as a cause of DNA damage, associated with the appearance of TUNEL positive signals in defective mammalian spermatozoa (Gorczyca et al., 1993).

\section{Apoptosis and DNA damage}

In fact, if apoptosis is induced in spermatozoa by exposure to wortmannin no TUNEL positivity is seen, even though other facets of apoptosis, such as caspase activation and PS externalization are clearly evident (Koppers et al., 2011). There are three major reasons why apoptotic mammalian spermatozoa do not express an increase in DNA fragmentation as evidenced by the TUNEL assay. Firstly, the spermatozoon possesses a unique architecture with the mitochondria and cytoplasm in a distinct subcellular compartment (the midpiece) from the nucleus. As a result, even though endonucleases such as EndoG or CAD can be readily detected in apoptotic human spermatozoa they remain resolutely locked in the sperm midpiece and tail and never gain access to the nuclear compartment (Koppers et al., 2011). Secondly, spermatozoa possess a highly truncated base excision repair pathway, which features OGG1 but lacks APE1 (Smith et al., 2013). This is significant because APE1 is needed to create the 3'-hydroxyl group targeted by terminal transferases in the TUNEL reaction. Finally, sperm chromatin is so condensed it reaches the physical limits of compaction, with the result so that the DNA exists in a semi- crystalline state. Under these circumstances it is very difficult for the bulky reagents used in the TUNEL assay to penetrate the chromatin and register the presence of a DNA strand break. However, if the chromatin is chemically decondensed, TUNEL signals can be generated with human spermatozoa, in large part from cells that are no longer viable (Mitchell et al., 2011). If mitochondria-activated endonucleases cannot access the nuclear compartment and spermatozoa do not possess APE1, how can such TUNEL signals be generated?

Since DNA fragmentation can only be induced via nuclease activity or free radical attack, we propose the following chain of cause and effect when spermatozoa come under oxidative stress. First of all, the mitochondria respond to such stress by generating ROS in a self-perpetuating redox cycle and inducing oxidative damage in the DNA of live cells. This is why most of the DNA damage in human spermatozoa appears to be oxidatively induced (De luliis et al., 2009). The base excision repair enzyme OGG1 is then activated and cleaves the oxidized base out of the DNA, creating an abasic site. At this point, the base excision repair pathway comes to a halt and the DNA damage will remain unresolved unless the spermatozoon manages to fertilize an oocyte; if this occurs the repair process will be driven to completion by the latter. If fertilization does not occur then the combination of ROS, lipid aldehydes and caspase activity associated with apoptosis leads to cell death accompanied by the expression of PS on the cell surface. In this perimortem state, reached around 48 hours after the initiation of apoptosis, the spermatozoa become TUNEL positive, possibly as a result of the late activation of a nuclease which is integrated into the chromatin and/or as a result of exogenous endonucleases released by the reproductive tract gaining access to cells that are, by this point, disintegrating (Dominguez and Ward, 2009; Smith et al., 2013).

\section{Summary}

In summary, apoptosis plays a number of critical roles during the life history of male germ cells. During early development, the apoptotic process ensures that there is an optimal ratio of Sertioli cells to germ cells. In adult life, the same process ensures the selective deletion of differentiating germ cells that have been damaged for a wide variety of reasons and in this way safeguards the integrity of the male contribution to the embryonic genome. In mature spermatozoa, the apoptotic process accelerates the functional demise of cells that have suffered from oxidative stress and are carrying oxidatively damaged DNA. Given the adverse outcomes that have been associated with DNA damage in spermatozoa including subfertility, impaired preimplantation development, miscarriage and disease in the offspring (Zini and Sigman, 2009), an understanding of the factors responsible for creating oxidative stress and initiating apoptosis in spermatozoa is extremely important to achieve. Specifically, the finding that most DNA damage in live cells is occurring during the early stages of apoptosis as a result of oxidative stress, has major implications for the diagnosis, treatment and prevention of this condition. Finally, apoptosis ensures that senescent moribund spermatozoa die a carefully regulated death, so that they can be efficiently and silently removed by a phagocytotic process that recognizes surface markers, like PS, generated during the apoptotic cascade. Thus while apoptosis in the male germ line may exhibit some unusual features, it is clearly a critical element of the reproductive process.

\section{References}

AGARWAL, A., DESAI, N.R., MAKKER, K., VARGHESE, A., MOURADI, R., SABANEGH, E., SHARMA, R. (2009) Effects of radiofrequency electromagnetic waves (RF-EMW) from cellular phones on human ejaculated semen: an in vitro pilot study. Fertil Steril 92: 1318-1325.

AITKEN, R.J. (2011) The capacitation-apoptosis highway: oxysterols and mammalian sperm function. Biol Reprod 85: 9-12.

AITKEN, R.J., CURRY, B.J. (2011) Redox regulation of human sperm function: from the physiological control of sperm capacitation to the etiology of infertility and DNA damage in the germ line. Antioxid Redox Signal 14: 367-381.

AITKEN, R.J., FINDLAY, J.K., HUTT, K.J., KERR, J.B. (2011) Apoptosis in the germ line. Reproduction 141: 139-150.

AITKEN, R.J., HARKISS, D., KNOX, W., PATERSON, M., IRVINE, D.S. (1998)A novel signal transduction cascade in capacitating human spermatozoa characterised by a redox-regulated, cAMP-mediated induction of tyrosine phosphorylation. $J$ Cell Sci 111: 645-656.

AITKEN, R.J., PATERSON, M., FISHER, H., BUCKINGHAM, D.W., VAN DUIN, M (1995) Redox regulation of tyrosine phosphorylation in human spermatozoa and its role in the control of human sperm function. J Cell Sci 108: 2017-2025.

AITKEN, R.J., WHITING, S., DE IULIIS, G.N., McCLYMONT, S., MITCHELL, L.A., BAKER, M.A. (2012) Electrophilic aldehydes generated by sperm metabolism activate mitochondrial reactive oxygen species generation and apoptosis by targeting succinate dehydrogenase. J Biol Chem 287: 33048-33060.

AITKEN, R.J., WINGATE, J.K., DEIULIIS, G.N., KOPPERS, A.J., McLAUGHLIN, E.A. 
(2006) Cis-unsaturated fatty acids stimulate reactive oxygen species generation and lipid peroxidation in human spermatozoa. J Clin Endocrinol Metab91:4154-4163.

ALAM, M.S., OHSAKO, S., TAY, T.W., TSUNEKAWA, N., KANAI, Y., KUROHMARU, M. (2010) Di(n-butyl) phthalate induces vimentin filaments disruption in rat sertoli cells: a possible relation with spermatogenic cell apoptosis. Anat Histol Embryol 39: 186-193.

ALMEIDA, C., SOUSA, M., BARROS, A. (2009) Phosphatidylserine translocation in human spermatozoa from impaired spermatogenesis. Reprod Biomed Online 19: 770-777.

BAKER, M.A., NIXON, B., NAUMOVSKI, N., AITKEN, R.J. (2012) Proteomic insights into the maturation and capacitation of mammalian spermatozoa. SystBiol Reprod Med 58: 211-217.

BAILEY, J.L. (2010) Factors regulating sperm capacitation. Syst Biol Reprod Med 56: 334-348.

BALASURIYA, A., SERHAL, P., DOSHI, A., HARPER, J.C. (2013) Processes involved in assisted reproduction technologies significantly increase sperm DNA fragmentation and phosphatidylserine translocation. Andrologia (doi: 10.1111/and.12052).

BARROSO, G., MORSHEDI, M., OEHNINGER, S. (2000) Analysis of DNAfragmentation, plasma membrane translocation of phosphatidylserine and oxidative stress in human spermatozoa. Hum Reprod 15: 1338-1344.

BOERKE, A., BROUWERS, J.F., OLKKONEN, V.M., VAN DE LEST, C.H., SOSTARIC, E., SCHOEVERS, E.J., HELMS, J.B., GADELLA, B.M. (2013) Involvement of bicarbonate-induced radical signaling in oxysterol formation and sterol depletion of capacitating mammalian sperm during in vitro fertilization. Biol Reprod (doi: 10.1095/biolreprod.112.101253).

CHEN, Z.H., NIKI, E. (2006) 4-hydroxynonenal (4-HNE) has been widely accepted as an inducer of oxidative stress. Is this the whole truth about it or can 4-HNE also exert protective effects? IUBMB Life 58: 372-373.

CHIMENTO, A., SIRIANNI, R., DELALANDE, C., SILANDRE, D., BOIS, C., ANDÒ, S., MAGGIOLINI, M., CARREAU, S., PEZZI, V. (2010) 17 beta-estradiol activates rapid signaling pathways involved in rat pachytene spermatocytes apoptosis through GPR30 and ER alpha. Mol Cell Endocrinol 320: 136-144.

DE IULIIS, G.N., NEWEY, R.J., KING, B.V., AITKEN, R.J. (2009) Mobile phone radiation induces reactive oxygen species production and DNA damage in human spermatozoa in vitro. PLoS One 4: e6446.

DE IULIIS, G.N., THOMSON, L.K., MITCHELL, L.A., FINNIE, J.M., KOPPERS, A.J., HEDGES, A., NIXON, B., AITKEN, R.J. (2009) DNA damage in human spermatozoa is highly correlated with the efficiency of chromatin remodeling and the formation of 8-hydroxy-2'-deoxyguanosine, a marker of oxidative stress. Biol Reprod 81: 517-524.

DEVITT, A., MARSHALL, L.J. (2011) The innate immune system and the clearance of apoptotic cells. J Leukoc Biol 90: 447-457.

DOMINGUEZ, K., WARD, W.S. (2009) A novel nuclease activity that is activated by $\mathrm{Ca}(2+)$ chelated to EGTA. Syst Biol Reprod Med 55: 193-199.

DU PLESSIS, S.S., MCALLISTER, D.A., LUU, A., SAVIA, J., AGARWAL, A., LAMPIAO, F. (2010). Effects of $\mathrm{H}_{2} \mathrm{O}_{2}$ exposure on human sperm motility parameters, reactive oxygen species levels and nitric oxide levels. Andrologia 42: 206-210.

ECROYD, H.W., JONES, R.C., AITKEN, R.J. (2003) Endogenous redox activity in mouse spermatozoa and its role in regulating the tyrosine phosphorylation events associated with sperm capacitation. Biol Reprod 69: 347-354.

ESPINOZA, J.A., PAASCH, U., VILLEGAS, J.V. (2009) Mitochondrial membrane potential disruption pattern in human sperm. Hum Reprod 24: 2079-2085.

FADOK, V.A., SAVILL, J.S., HASLETT, C., BRATTON, D.L., DOHERTY, D.E., CAMPBELL, P.A., HENSON, P.M. (1992) Different populations of macrophages use either the vitronectin receptor or the phosphatidylserine receptor to recognize and remove apoptotic cells. J Immunol 149: 4029-4035.

FICHOROVA, R.N., BAJPAI, M., CHANDRA, N., HSIU, J.G., SPANGLER, M., RATNAM, V., DONCEL, G.F. (2004) Interleukin (IL)-1, IL-6, and IL-8 predict mucosal toxicity of vaginal microbicidal contraceptives. Biol Reprod 71: 761-769.

FRACZEK, M., SZUMALA-KAKOL, A., JEDRZEJCZAK, P., KAMIENICZNA, M., KURPISZ, M. (2007) Bacteria trigger oxygen radical release and sperm lipid peroxidation in in vitro model of semen inflammation. Fertil Steril 88: 1076-1085.

FRAGA, C.G., MOTCHNIK, P.A., WYROBEK, A.J., REMPEL, D.M., AMES, B.N. (1996) Smoking and low antioxidant levels increase oxidative damage to sperm DNA. Mutat Res 351: 199-203.
GHOSH, D., DAS, U.B., MISRO, M. (2002) Protective role of alpha-tocopherolsuccinate (provitamin-E) in cyclophosphamide induced testicular gametogenic and steroidogenic disorders: a correlative approach to oxidative stress. Free Radic Res 36: 1209-1218.

GRAD, I., CEDERROTH, C.R., WALICKI, J., GREY, C., BARLUENGA, S., WINSSINGER, N., DE MASSY, B., NEF, S., PICARD, D. The molecular chaperone Hsp90 $\alpha$ is required for meiotic progression of spermatocytes beyond pachytene in the mouse. PLoS One 5: e15770.

GORCZYCA, W., TRAGANOS, F., JESIONOWSKA, H., DARZYNKIEWICZ, Z. (1993) Presence of DNA strand breaks and increased sensitivity of DNA in situ to denaturation in abnormal human sperm cells: analogy to apoptosis of somatic cells. Exp Cell Res 207: 202-205.

GRUNEWALD, S., SHARMA, R., PAASCH, U., GLANDER, H.J., AGARWAL, A. (2009) Impact of caspase activation in human spermatozoa. Microsc Res Tech72:868-888.

GUTTI, R.K., TSAI-MORRIS, C.H., DUFAU, M.L. (2008) Gonadotropin-regulated testicular helicase (DDX25), an essential regulator of spermatogenesis, prevents testicular germ cell apoptosis. J Biol Chem 283: 17055-17064.

HELD, T., BARAKAT, A.Z., MOHAMED, B.A., PAPROTTA, I., MEINHARDT, A., ENGEL, W., ADHAM, I.M. (2011) Heat-shock protein HSPA4 is required for progression of spermatogenesis. Reproduction 142: 133-144.

HUGHES, L.M., GRIFFITH, R., CAREY, A., BUTLER, T., DONNE, S.W., BEAGLEY, K.W., AITKEN, R.J. (2009) The spermostatic and microbicidal actions of quinones and maleimides: toward a dual-purpose contraceptive agent. Mol Pharmacol 76: 113-124.

JEYARAJ, D.A., GROSSMAN, G., PETRUSZ, P. (2003) Dynamics of testicular germ cell apoptosis in normal mice and transgenic mice overexpressing rat androgenbinding protein. Reprod Biol Endocrinol 1: 48.

KOSIR, R., JUVAN, P., PERSE, M., BUDEFELD, T., MAJDIC, G., FINK, M., SASSONECORSI, P., ROZMAN, D. (2012) Novel insights into the downstream pathways and targets controlled by transcription factors CREM in the testis. PLoS One 7: e31798.

KOPPERS, A.J., DE IULIIS, G.N., FINNIE, J.M., McLAUGHLIN, E.A., AITKEN, R.J. (2008) Significance of mitochondrial reactive oxygen species in the generation of oxidative stress in spermatozoa. J Clin Endocrinol Metab 93: 3199-3207.

KOPPERS, A.J., MITCHELL, L.A., WANG, P., LIN, M., AITKEN, R.J. (2011) Phosphoinositide 3-kinase signalling pathway involvement in a truncated apoptotic cascade associated with motility loss and oxidative DNA damage in human spermatozoa. Biochem J 436: 687-698.

LANDAR, A., ZMIJEWSKI, J.W., DICKINSON, D.A., LE GOFFE, C., JOHNSON, M.S., MILNE, G.L., ZANONI, G., VIDARI, G., MORROW, J.D., DARLEY-USMAR, V.M. (2006) Interaction of electrophilic lipid oxidation products with mitochondria in endothelial cells and formation of reactive oxygen species. Am J Physiol Heart Circ Physiol 290: H1777-1787.

LAROCCA, J., BOYAJIAN, A., BROWN, C., SMITH, S.D., HIXON, M. (2011) Effects of in utero exposure to Bisphenol Aor diethylstilbestrol on the adult male reproductive system. Birth Defects Res B Dev Reprod Toxicol 92: 526-533.

LEWIS, B., AITKEN, R.J. (2001) A redox-regulated tyrosine phosphorylation cascade in rat spermatozoa. J Androl 22: 611-622.

LI, Y.J., SONG, T.B., CAI, Y.Y., ZHOU, J.S., SONG, X., ZHAO, X., WU, X.L. (2009) Bisphenol $A$ exposure induces apoptosis and upregulation of Fas/FasL and caspase-3 expression in the testes of mice. Toxicol Sci 108: 427-436.

LIN, W.W., LAMB, D.J., WHEELER, T.M., ABRAMS, J., LIPSHULTZ, L.I., KIM, E.D. (1997) Apoptotic frequency is increased in spermatogenic maturation arrest and hypospermatogenic states. J Urol 158: 1791-1793.

LIN, Y.C., YAO, P.L., RICHBURG, J.H. (2010) FasL gene-deficient mice display a limited disruption in spermatogenesis and inhibition of mono-(2-ethylhexyl) phthalate-induced germ cell apoptosis. Toxicol Sci 114: 335-345.

LINSCHOOTEN, J.O., LAUBENTHAL, J., CEMELI, E., BAUMGARTNER, A., ANDERSON, D., SIPINEN, V.E., BRUNBORG, G., HAENEN, G.R., FTHENOU, E., BRIEDÉ, J.J., VAN SCHOOTEN, F.J., GODSCHALK, R.W. (2011) Incomplete protection of genetic integrity of mature spermatozoa against oxidative stress. Reprod Toxicol 32: 106-111.

LIU, Z., ZHOU, S., LIAO, L., CHEN, X., MEISTRICH, M., XU, J. (2010) Jmjd1a demethylase-regulated histone modification is essential for cAMP-response element modulator-regulated gene expression and spermatogenesis. J Biol Chem 285: 2758-2770. 
MA, A., YANG, X., WANG, Z., SHI, D., CHEN, Y. (2008) Adult exposure to diethylstilbestrol induces spermatogenic cell apoptosis in vivo through increased oxidative stress in male hamster. Reprod Toxicol 25: 367-373.

MITCHELL, L.A., DE IULIIS, G.N., AITKEN, R.J. (2011) The TUNEL assay consistently underestimates DNA damage in human spermatozoa and is influenced by DNA compaction and cell vitality: development of an improved methodology. Int $J$ Androl 34: 2-13.

MOSTAFA, T., ANIS, T.H., EL-NASHAR, A., IMAM, H., OTHMAN, I.A. (2001) Varicocelectomy reduces reactive oxygen species levels and increases antioxidant activity of seminal plasma from infertile men with varicocele. Int $J$ Androl 24: 261-265.

MUSSET, B., CLARK, R.A., DECOURSEY, T.E., PETHEO, G.L., GEISZT, M., CHEN, Y., CORNELL, J.E., EDDY, C.A., BRZYSKI, R.G., EL JAMALI, A. (2012) NOX5 in human spermatozoa: expression, function, and regulation. $J$ Biol Chem 287: 9376-9388.

ORTEGA FERRUSOLA, C., GONZÁLEZ FERNÁNDEZ, L., SALAZAR SANDOVAL, C., MACÍAS GARCÍA, B., RODRÍGUEZ MARTÍNEZ, H., TAPIA, J.A., PEÑA, F.J. (2010) Inhibition of the mitochondrial permeability transition pore reduces "apoptosis like" changes during cryopreservation of stallion spermatozoa. Theriogenology 74: 458-465.

PALMER, N.O., BAKOS, H.W., OWENS, J.A., SETCHELL, B.P., LANE, M. (2012) Diet and exercise in an obese mouse fed a high-fat diet improve metabolic health and reverse perturbed sperm function. Am J Physiol Endocrinol Metab302: E768-780.

PUJIANTO, D.A., CURRY, B.J., AITKEN, R.J. (2010) Prolactin exerts a prosurvival effect on human spermatozoa via mechanisms that involve the stimulation of Akt phosphorylation and suppression of caspase activation and capacitation. Endocrinology 151: 1269-1279.

PAASCH, U., GRUNEWALD, S., AGARWAL, A., GLANDERA, H.J. (2004) Activation pattern of caspases in human spermatozoa. Fertil Steril 81; Suppl 1: 802-809.

REID, A.T., REDGROVE, K., AITKEN, R.J., NIXON, B. (2011) Cellular mechanisms regulating sperm-zona pellucida interaction. Asian $J$ Androl 13: 88-96.

RODRIGUEZ, I., ODY, C., ARAKI, K., GARCIA, I., VASSALLI, P. (1997) An early and massive wave of germinal cell apoptosis is required for the development of functional spermatogenesis. EMBO J 16: 2262-2270.

ROZEBOOM, K.J., TROEDSSON, M.H., CRABO, B.G. (1998) Characterization of uterine leukocyte infiltration in gilts after artificial insemination. $J$ Reprod Fertil 114: 195-199.

SAVILL, J., DRANSFIELD, I., GREGORY, C., HASLETT, C. (2002) A blast from the past: clearance of apoptotic cells regulates immune responses. Nat Rev Immunol 2: 965-975.

SHAHA, C., TRIPATHI, R., MISHRA, D.P. (2010) Male germ cell apoptosis: regulation and biology. Philos Trans R Soc Lond B Biol Sci 365: 1501-1515.

SMITH, T.B., DUN, M.D. SMITH, N.D. CURRY, B.J. CONNAUGHTON H.S., AITKEN, R.J. (2013) The presence of a truncated base excision repair pathway in human spermatozoa, mediated by OGG1. J Cell Sci 126: 1488-1497.

SPIERINGS, D.C,. DE VRIES, E.G., VELLENGA, E., DE JONG, S. (2003) The attractive Achilles heel of germ cell tumours: an inherent sensitivity to apoptosisinducing stimuli. J Pathol 200: 137-148.
SUAREZ, S.S. (2008) Control of hyperactivation in sperm. Hum Reprod Update 14: 647-657.

THOMSON, L.K., FLEMING, S.D., AITKEN, R.J., DE IULIIS, G.N., ZIESCHANG J.A., CLARK, A.M. (2009) Cryopreservation-induced human sperm DNA damage is predominantly mediated by oxidative stress rather than apoptosis. Hum Reprod 24: 2061-2070.

THOMPSON, L.A., BARRATT, C.L., BOLTON, A.E., COOKE, I.D. (1992) The leukocytic reaction of the human uterine cervix. Am J Reprod Immunol 28: 85-89.

TSOUNAPI, P., SAITO, M., DIMITRIADIS, F., KOUKOS, S., SHIMIZU, S., SATOH, K., TAKENAKA, A., SOFIKITIS, N (2012) Antioxidant treatment with edaravone or taurine ameliorates diabetes-induced testicular dysfunction in the rat. Mol Cell Biochem 369: 195-204.

UCHIDA, K. (2003) 4-Hydroxy-2-nonenal: a product and mediator of oxidative stress. Prog Lipid Res 42: 318-343.

VANDAMME, L., RAMJEE, G., ALARY, M., VUYLSTEKE, B., CHANDEYING, V., REES H., SIRIVONGRANGSON, P., MUKENGE-TSHIBAKA, L., ETTIĖGNE-TRAORÉ, V., UAHEOWITCHAI, C., KARIM, S.S., MÂSSE, B., PERRIËNS, J., LAGA, M. COL-1492 STUDY GROUP. (2002) Effectiveness of COL-1492, a nonoxynol-9 vaginal gel, on HIV-1 transmission in female sex workers: a randomised controlled trial. Lancet 360: 971-977.

VILLEGAS, J., SCHULZ, M., SOTO, L., SANCHEZ, R. (2005) Bacteria induce expression of apoptosis in human spermatozoa. Apoptosis 10: 105-110.

WANG, C., CUI, Y.G., WANG, X.H., JIA, Y., SINHA HIKIM, A., LUE, Y.H., TONG, J.S., QIAN, L.X., SHA, J.H., ZHOU, Z.M., HULL, L., LEUNG, A., SWERDLOFF, R.S. (2007) Transient scrotal hyperthermia and levonorgestrel enhance testosteroneinduced spermatogenesis suppression in men through increased germ cell apoptosis. J Clin Endocrinol Metab 92: 3292-3304.

WEIR, C.P., ROBAIRE, B. (2007) Spermatozoa have decreased antioxidant enzymatic capacity and increased reactive oxygen species production during aging in the Brown Norway rat. J Androl 28: 229-240.

WENG, S.L., TAYLOR, S.L., MORSHEDI, M., SCHUFFNER, A., DURAN, E.H., BEEBE, S., OEHNINGER, S. (2002) Caspase activity and apoptotic markers in ejaculated human sperm. Mol Hum Reprod 8: 984-991.

XU, G., ZHOU, G., JIN, T., ZHOU, T., HAMMARSTRÖM, S., BERGH, A., NORDBERG, G. (1999) Apoptosis and p53 gene expression in male reproductive tissues of cadmium exposed rats. Biometals 12: 131-139.

ZHANG, L., YU, L., YU, C.A. (1998). Generation of superoxide anion by succinatecytochrome c reductase from bovine heart mitochondria. J Biol Chem 273 33972-33976.

ZINI, A., SIGMAN, M. (2009) Are tests of sperm DNA damage clinically useful? Pros and cons. J Androl 30: 219-229.

ZOCCARATO, F., CAVALLINI, L., ALEXANDRE, A. (2009) Succinate is the controller of $\mathrm{O}_{2}-/ \mathrm{H}_{2} \mathrm{O}_{2}$ release at mitochondrial complex I: negative modulation by malate, positive by cyanide. J Bioenerg Biomembr 41: 387-393.

ZOROV, D.B., FILBURN, C.R., KLOTZ, L.O., ZWEIER, J.L., SOLLOTT, S.J. (2000) Reactive oxygen species (ROS)-induced ROS release: a new phenomenon accompanying induction of the mitochondrial permeability transition in cardiac myocytes. J Exp Med 192: 1001-1014. 
Further Related Reading, published previously in the Int. J. Dev. Biol.

Above the borderland between normal and neoplastic development

Juan Aréchaga and Ivan Damjanov

Int. J. Dev. Biol. (2012) 56: 939-948

Molecular and cellular machinery of gonadal differentiation in mammals

Rafal P. Piprek

Int. J. Dev. Biol. (2010) 54: 779-786

Analysis of SOX2 expression in developing human testis and germ cell neoplasia Si B. Sonne, Rebecca M. Perrett, John E. Nielsen, Melissa A. Baxter, David M. Kristensen, Henrik Leffers, Neil A. Hanley and Ewa Rajpert-De-Meyts Int. J. Dev. Biol. (2010) 54: 755-760

Germinal tumor invasion and the role of the testicular stroma

Alejandro Díez-Torre, Unai Silván, Olivier De Wever, Erik Bruyneel, Marc Mareel and Juan Aréchaga

Int. J. Dev. Biol. (2004) 48: 545-557

The role of stem cell factor and of alternative c-kit gene products in the establishment, maintenance and function of germ cells C Sette, S Dolci, R Geremia and P Rossi Int. J. Dev. Biol. (2000) 44: 599-608

5 yr ISI Impact Factor $(2011)=2.959$
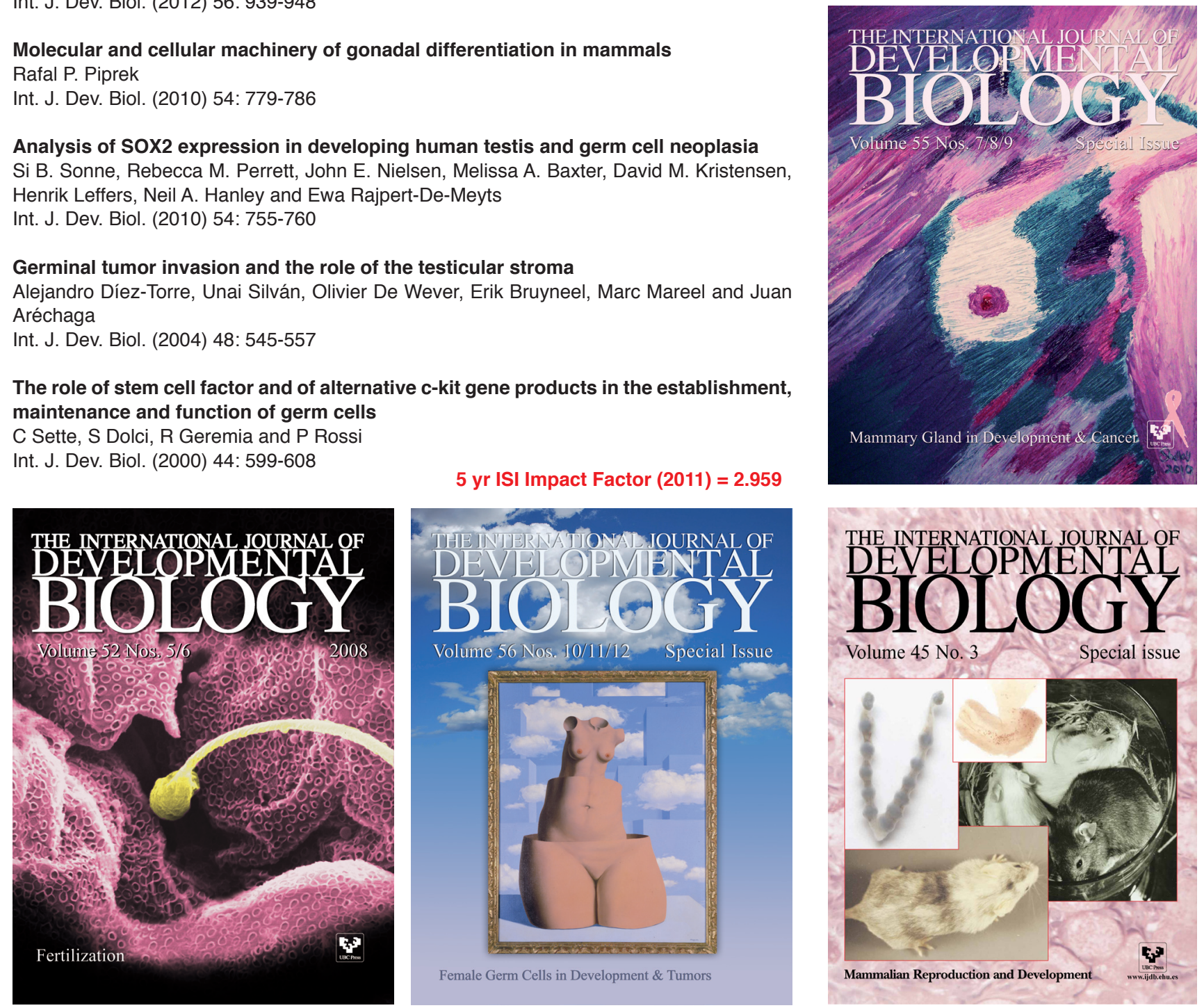